\title{
Ultrasonography Assisted Reduction Vs Blind Manipulation in Closed Reduction of Colles Fractures - A Comparative Study
}

\author{
Venkateswara Rao Dasari ${ }^{1}$, Shyam Kumar Chintaㄹ, Sudhakar Kanaparthi³ ${ }^{3}$ Arun Joy ${ }^{4}$ \\ 1, 2, 3,4 Department of Orthopaedics, Siddhartha Medical College, Vijayawada, Andhra Pradesh, India.
}

\section{ABSTRACT}

\section{BACKGROUND}

Colles fracture is the most common wrist fracture in adults, predominantly affecting elderly women. Our study intends to reinforce the role of ultrasonography assisted reduction of Colles fractures as a suitable alternative to blind manipulation, as it can verify the adequacy of reduction in a single sitting in real time, and avoid multiple reduction sessions.

\section{METHODS}

20 adult patients diagnosed with Colles fracture were enrolled in this case control study. Patients were divided into two groups of 10 each, study and control groups. The sample size was limited due to the Covid-19 pandemic of 2020. Study group was subjected to ultrasonography assisted reduction. Control group was subjected to blind manipulation and reduction.

\section{RESULTS}

Baseline characteristics between two groups were similar. The rate of repeat reduction was reduced in the ultrasound group (20\% VS $40 \%$; $\mathrm{P}=.329$ ). The post reduction radiographic indices were similar between the two groups, although the ultrasound group had improved volar tilt (mean, $2.8^{0}$ VS $1.6^{0} ; \mathrm{P}=.394$ ). The operative rate was reduced in the ultrasound groups (10\% VS $30 \%$; $=.263$ ). These results, though similar to existing studies into the topic, were not statistically significant, probably due to low sample size.

\section{CONCLUSIONS}

Despite the inability of our study to arrive at statistically significant results, we have positive findings for the parameters of volar tilt, number of multiple reduction attempts and number of cases proceeding to surgery. These findings are in line with other studies that were successful in establishing statistical significance for the above parameters. In view of this, a recommendation can be made to prefer ultrasonography assisted reduction over blind manipulation in initial management of Colles fractures, where the facility is available.

\section{KEY WORDS}

Colles Fractures, Ultrasonography, Blind Manipulation, Reduction, Volar Tilt, Operative Rate
Corresponding Author:

Dr. Arun Joy,

Room No. S1,

Post Graduate Men's Hostel, Siddhartha Medical College, Gunadala, Vijayawada-520008, Andhra Pradesh, India.

E-mail:www.avin@gmail.com

DOI: $10.14260 / j e m d s / 2022 / 25$

How to Cite This Article: Dasari VR, Chinta SK, Kanaparthi S, et al. Ultrasonography assisted reduction vs blind manipulation in closed reduction of Colles fractures - a comparative study. J Evolution Med Dent Sci 2022;11(01):132135, DOI: $10.14260 / \mathrm{jemds} / 2022 / 25$

Submission 26-02-2021,

Peer Review 15-01-2022,

Acceptance 22-01-2022,

Published 28-01-2022.

Copyright (c) 2022 Venkateswara Rao Dasari et al. This is an open access article distributed under Creative Commons Attribution License [Attribution 4.0 International (CC BY 4.0)] 


\section{BACKGROUND}

Colles fracture ${ }^{1}$ is the most common wrist fracture in adults, predominantly affecting elderly women. ${ }^{2}$

It is an extra articular fracture affecting the distal radial metaphysis, with dorsal angulation and shortening. ${ }^{3}$ The resultant deformity is known as 'dinner fork' deformity. ${ }^{4}$ The most common mechanism of injury is fall on an outstretched hand. ${ }^{5}$

Blind manipulation and reduction may be inaccurate and hence, multiple reduction attempts maybe needed. This will cause discomfort to the patient. It can result in soft tissue injury, patient discomfort and additional investment in personnel, time and resources. The method of analgesia that can be employed for the reduction of this fracture is a haematoma block.6, The effect of this block is temporary, and multiple prolonged attempts at reduction may cause the analgesia to dissipate, leading to increased pain with each reduction attempt. It is therefore vital to minimize the number of reduction attempts. However, this is not always possible for an inexperienced surgeon attempting to reduce this fracture blindly. Also, if the blind manipulation and reduction was carried out in the operating room under anaesthesia, multiple reduction attempts may cause prolonged anaesthesia time and increases chances of related complications. Ultrasonography can offer valuable assistance to prevent this scenario.

Traditionally, the fracture is reduced blindly, or under fluoroscopy guidance, under local or regional anaesthesia, followed by post reduction radiographs to assess the adequacy of reduction. ${ }^{7}$

Fluoroscopy can cause radiation exposure, ${ }^{8}$ and the necessary hardware is cumbersome and may not be available in every center. ${ }^{9}$ High intensity fluoroscopy may cause skin burns, ${ }^{10}$ while cumulative radiation exposure over several years may cause malignancy. ${ }^{11}$ Despite the excellent images that fluoroscopy can provide, its radiation risks make it worthwhile to seek an alternative. The surgeon has more risk due to cumulative exposure over several years, in comparison to the patient who is usually exposed to fluoroscopy only once in his life. It is thus irrational to use fluoroscopy for fractures which can be reduced in an outpatient setting, if an alternative method of reduction is made available.

Hence, ultrasonography assisted reduction was examined as a probable alternative. It has no risk of radiation exposure. The necessary hardware is also available in rural areas, ${ }^{12}$ and is not cumbersome to use, in comparison with fluoroscopy. Also, the fluoroscope is expensive and its usability is questionable in a primary health centre. An ultrasonography machine can be repurposed to serve multiple specialties and has much more utility for a primary care hospital. If ultrasonography can be repurposed to aid in the reduction of Colles fractures, it can potentially enable personnel in primary care hospitals to reduce this fracture accurately, and avoid complications related to malreduction and multiple reduction attempts. It can also potentially reduce the referrals to higher centres as a consequence of malreduction, and the subsequent complications which may arise.

Our study intends to reinforce the role of ultrasonography assisted reduction of Colles fractures as a suitable alternative to blind manipulation, as it has the potential to verify the adequacy of reduction in a single sitting in real time, and to avoid multiple reduction sessions.

\section{METHODS}

The study was a case control study, conducted in the Department of Orthopaedics, Government General Hospital, Siddhartha Medical College, Vijayawada, Andhra Pradesh.

The period of study was from November 2018 to November 2020. Ethical Committee clearance was obtained from the Institutional Ethics Committee at our College. Written informed consent was obtained from all participants.

A sample size of 60 patients was planned. However, this had to be reduced to 20 owing to the dearth of clinical material following the Covid-19 pandemic of 2020.

\section{Inclusion Criteria}

Patients above 18 years of age with clinically and radiographically diagnosed Colles fractures.

\section{Exclusion Criteria}

Neurovascular compromise, open fractures, age less than 18 years, poor compliance, and polytrauma.

\section{Procedure}

20 adult patients diagnosed with Colles fracture were enrolled in the study. Patients were divided into two groups of 10 each, study and control groups. The sample size was limited due to the Covid-19 pandemic of 2020. Study group was subject to ultrasonography assisted reduction. Control group was subjected to blind manipulation and reduction.

Antero - posterior, lateral radiographs of the wrist was first obtained for fracture confirmation. Analgesia was then provided using hematoma block. ${ }^{13}$ For the study group, pre reduction ultrasonogram of the fracture site is then obtained by visualizing using 7.5-megahertz linear array probe ${ }^{14}$ by orienting the probe along the longitudinal plane along the dorsal and radial aspects of the radius. No such assessment was done for the control group.

Following this, fracture was reduced as usual using traction - counter traction and manipulation. ${ }^{15}$ Post reduction, fracture site was visualized and the reduction was assessed using ultrasonography for the study group.

If proximal and distal cortices were aligned in a straight line, it meant successful reduction. If not aligned, reduction and ultrasonography were repeated as often as needed until the cortices are aligned.

Post reduction radiographs were then obtained for both groups, and adequacy of reduction was assessed. The acceptable criteria 16 for successful reduction was volar tilt > 0 degrees, radial inclination of $15-25$ degrees and radial height $>5 \mathrm{~mm}$. If reduction was insufficient on post reduction radiographs, another attempt was made. Final decision regarding operative or conservative management was made by the orthopaedics assistant professor, following evaluation of post reduction radiographs. 
The following parameters were compared between study and control groups -

1. Post reduction radiological indices (volar tilt, radial height, radial inclination)

2. Number of reduction attempts.

3. Final management (conservative, operative)

\section{Description of Radiological Indices}

1. Volar tilt -It is a measurement made on the lateral projection of the wrist as an angle of the distal radial surface with respect to a line perpendicular to the shaft. A normal range is considered at around $10-25^{\circ 17}$

2. Radial height - It is the distance between two lines drawn perpendicular to the long axis of the radius on the AP projection from the apex of the radial styloid and level of the ulnar aspect of the articular surface. ${ }^{18}$

3. Radial inclination - It is a measurement made on the AP projection of the wrist as an angle of the distal radial surface with respect to a line perpendicular to the shaft. A normal range is considered at around $21-25^{\circ} .19$

\section{Statistical Analysis}

Results were analysed using SPSS 22 statistical analysis. For categorical data, chi square test was used to determine significance. For numerical data Student $t$ test was used to test for significance.

\section{RESULTS}

The baseline characteristics of the two groups are depicted in Table 1. There is no statistically significant difference between these two groups on the basis of these characteristics.

Table 2 shows post reduction fracture indices. The radial inclination and radial height were similar for both groups post reduction. The volar tit was noticeably better in the study group $\left(2.8^{0}\right.$ vs $\left.1.6^{\circ}\right)$, but this was not statistically significant. $(\mathrm{P}=0.394$, not significant at $\mathrm{P}<0.05)$.

Table 3 shows the reduction outcomes. There is a noticeable decline in the number of multiple reduction attempts ( 2 vs 4$)$ in the study group $(\mathrm{P}=0.329)$. The number of cases proceeding to surgery were also lower (1 vs 3 ) in the study group vs control group $(\mathrm{P}=0.263)$. However, none of these results were statistically significant at $\mathrm{P}<0.05$.

\begin{tabular}{|c|c|c|c|c|}
\hline & & $\begin{array}{l}\text { Ultrasono- } \\
\text { graphy (\%) }\end{array}$ & $\begin{array}{c}\text { Blind } \\
\text { Manipulation (\%) }\end{array}$ & $\mathbf{P}$ \\
\hline \multirow{3}{*}{$\begin{array}{c}\text { Average age } \\
\text { Sex }\end{array}$} & & 52.8 & 55.5 & \multirow{3}{*}{$\begin{array}{c}0.516 \\
1\end{array}$} \\
\hline & Male & $4(40)$ & $4(40)$ & \\
\hline & Female & $6(60)$ & $6(60)$ & \\
\hline \multirow{2}{*}{$\begin{array}{l}\text { Mechanism } \\
\text { of trauma }\end{array}$} & Road traffic accident & $2(20)$ & $1(10)$ & \multirow{2}{*}{0.531} \\
\hline & Accidental fall & $8(80)$ & $9(90)$ & \\
\hline \multirow{2}{*}{$\begin{array}{l}\text { Side of } \\
\text { fracture }\end{array}$} & Right & $3(30 \%)$ & $2(20 \%)$ & \multirow{2}{*}{0.605} \\
\hline & Left & $7(70 \%)$ & $8(80 \%)$ & \\
\hline \multirow{3}{*}{$\begin{array}{c}\text { Fracture } \\
\text { indices }\end{array}$} & Volar tilt & -15.6 & -17.6 & 0.172 \\
\hline & Radial inclination & 13 & 14.1 & 0.409 \\
\hline & Radial height & 6.3 & 6.8 & 0.597 \\
\hline
\end{tabular}

\begin{tabular}{|cccc|}
\hline Fracture Indices & Ultrasonography & Blind Manipulation & P \\
Volar tilt & 2.8 & 1.6 & 0.394 \\
Radial inclination & 16.2 & 16.7 & 0.559 \\
Radial height & 10.9 & 10.8 & 0.661 \\
\hline Table 2. Post Reduction Radiographic Indices (significant at $\mathbf{P}<\mathbf{0 . 0 5}$ ) \\
\hline
\end{tabular}

\begin{tabular}{|ccccc|}
\hline Parameter & & $\begin{array}{c}\text { Ultrasono- } \\
\text { graphy (\%) }\end{array}$ & $\begin{array}{c}\text { Blind } \\
\text { Manipulation (\%) }\end{array}$ & P \\
\hline \multirow{2}{*}{ Number of reductions } & 1 & $8(80 \%)$ & $6(60 \%)$ & 0 \\
& $>1$ & $2(20 \%)$ & $4(40 \%)$ & 0.329 \\
\multirow{2}{*}{ Final management } & Conservative & $9(90 \%)$ & $7(70 \%)$ & \multirow{2}{*}{0.263} \\
\hline \multicolumn{2}{|c|}{ Table 3. Reduction Outcomes (significant at P<0.05) } \\
\hline
\end{tabular}

\begin{tabular}{|c|c|c|c|}
\hline \multirow[b]{2}{*}{ Study } & \multicolumn{2}{|c|}{ Average Volar Tilt } & \multirow[b]{2}{*}{ P Value } \\
\hline & $\begin{array}{l}\text { Ultrasonography } \\
\text { Assisted Reduction }\end{array}$ & $\begin{array}{c}\text { Blind } \\
\text { Manipulation }\end{array}$ & \\
\hline Ang et al. ${ }^{20}$ & 5.93 & 2.61 & 0.048 \\
\hline Sabzgabhaei et al. ${ }^{16}$ & 7.6 & 3.7 & 0.001 \\
\hline Present study & 2.8 & 1.6 & 0.394 \\
\hline
\end{tabular}

\begin{tabular}{|c|c|c|c|c|c|}
\hline \multirow{3}{*}{ Study } & \multicolumn{4}{|c|}{ Reduction Attempts } & \multirow{3}{*}{ P Value } \\
\hline & \multirow{2}{*}{\multicolumn{2}{|c|}{$\begin{array}{l}\text { Ultrasonography } \\
\text { Assisted Reduction }\end{array}$}} & \multirow{2}{*}{\multicolumn{2}{|c|}{$\begin{array}{c}\text { Blind } \\
\text { Manipulation }\end{array}$}} & \\
\hline & & & & & \\
\hline Sabzgabhaei et al. ${ }^{16}$ & $59(90.8)$ & $6(9.2)$ & $49(75.4 \%)$ & $16(24.6)$ & 0.014 \\
\hline Ang et al. ${ }^{20}$ & $61(98.4)$ & $1(1.6)$ & $93(91.2)$ & $9(8.8)$ & 0.056 \\
\hline Present study & $8(80 \%)$ & $2(20 \%)$ & $6(60 \%)$ & $4(40 \%)$ & 0.329 \\
\hline & e 5. Redu & ion Attem & pts vs Oth & r Studies & \\
\hline
\end{tabular}

\begin{tabular}{|c|c|c|c|c|c|}
\hline \multirow[b]{2}{*}{ Study } & \multicolumn{4}{|c|}{$\begin{array}{l}\text { Final Management } \\
\end{array}$} & \multirow[b]{2}{*}{$\begin{array}{c}\text { P } \\
\text { Value }\end{array}$} \\
\hline & $\begin{array}{r}\text { Ultras } \\
\text { Assiste } \\
\text { Surgical }\end{array}$ & $\begin{array}{l}\text { onography } \\
\text { d Reduction } \\
\text { Conservative }\end{array}$ & $\begin{array}{r}\text { Man } \\
\text { Surgical }\end{array}$ & $\begin{array}{l}\text { Blind } \\
\text { ipulation } \\
\text { Conservative }\end{array}$ & \\
\hline Ang et al. ${ }^{20}$ & 3 & 59 & 17 & 85 & 0.019 \\
\hline Sabzgabhaei et al. ${ }^{16}$ & 7 & 58 & 18 & 47 & 0.014 \\
\hline Present study & $1(10 \%)$ & $9(90 \%)$ & $3(30 \%)$ & $7(70 \%)$ & 0.263 \\
\hline & sle 6. Fin & Managem & vs Other & Studies & \\
\hline
\end{tabular}

\section{DISCUSSION}

In the present study, we discovered a noticeable improvement in the post reduction volar tilt in the study group. There was also a reduction in the number of multiple attempts and in the number of cases proceeding to surgery in the study group. This is in line with other studies ${ }^{16,20,21}$ into the topic, which established statistically significant improvements in the above mentioned parameters. These findings are detailed in the following tables, with $\mathrm{P}<0.05$ considered significant.

However, this statistical significance could not be proven in the present study. This could be due to the low sample size, which could have resulted in abnormally high $\mathrm{p}$ values.

Ultrasonography has already been established as an effective tool in detecting long bone fractures, particularly in paediatric population. ${ }^{22}$ It is also being used in detecting wrist fractures. ${ }^{23}$ The technique of ultrasonography for detecting fractures is simple enough, that even nurses can detect fractures using it. ${ }^{24}$ The ultrasonography machine is also more abundant in smaller hospitals, compared to any other imaging modality, ${ }^{25}$ and is free from the issue of radiation exposure that plagues fluoroscopy machines. ${ }^{26}$

As other studies have shown, ${ }^{16}$ blind manipulation and reduction can result in multiple reduction attempts, more need for post reduction radiographs, increased patient discomfort, and radiation exposure, in comparison with ultrasonography assisted reduction. Ultrasonography also offers the advantage of real time observation while reducing the fracture. A major drawback of ultrasonography is its inability to penetrate bone, ${ }^{27}$ making it unsuitable for the reduction of intraarticular fractures. Also, some studies ${ }^{21}$ have documented a phenomenon where the cortices appear aligned under ultrasonography, but later turns out 
misaligned on radiographs. But this is assumed to be operator dependent. Despite the inability of our study to arrive at statistically significant results, it is noteworthy that in the study group, we have positive findings for the parameters of volar tilt, number of multiple reduction attempts and number of cases proceeding to surgery. These findings are in line with other studies that were successful in establishing statistical significance for the above parameters. In view of this, a recommendation could be made to prefer ultrasonography assisted reduction over blind manipulation in initial management of Colles fractures, where the facility is available.

\section{CONCLUSIONS}

Ultrasonography can be considered a suitable guidance tool for the reduction of distal radius fractures.

Data sharing statement provided by the authors is available with the full text of this article at jemds.com.

Financial or other competing interests: None.

Disclosure forms provided by the authors are available with the full text of this article at jemds.com.

\section{REFERENCES}

[1] Colles A. On the fracture of the carpal extremity of the radius. Edinb Med Surg J 1814;10(38):182-6. Clin Orthop Relat Res 2006;445:5-7.

[2] Handoll HH, Madhok R. Surgical interventions for treating distal radial fractures in adults. Cochrane Database Syst Rev 2003;(3):CD003209.

[3] Sharp JW, Edwards RM. Core curriculum illustration: "Colles," dorsally angulated fracture of the distal radius. Emerg Radiol 2019;26(6):699-700.

[4] Lim JA, Loh BLC, Sylvestor G, et al. Perioperative management of distal radius fractures. J Perioper Pract 2021;31(10).

[5] Summers K, Fowles SM. Colles' Fracture. [Updated 2021 Aug 11]. In: StatPearls [Internet]. Treasure Island (FL): StatPearls Publishing 2022. Available from: https://www.ncbi.nlm.nih.gov/books/NBK553071/

[6] Orbach H, Rozen N, Rinat B, et al. Hematoma block for distal radius fractures-prospective, randomized comparison of two different volumes of lidocaine. J Int Med Res 2018;46(11):4535-8.

[7] Blakeney WG. Stabilization and treatment of Colles' fractures in elderly patients. Clin Interv Aging 2010;5:337-44.

[8] Stahl CM, Meisinger QC, Andre MP, et al. Radiation risk to the fluoroscopy operator and staff. AJR Am J Roentgenol 2016;207(4):737-44.

[9] Gnanaraj J. Epidural steroid injection for back pain: low cost technique for rural areas. MD Current India 2017.

[10] Glazier JJ, Dixon SR. Skin injury following prolonged fluoroscopy: early and late appearances. QJM 2012;105(6):571-3.
[11] Johnson JN, Hornik CP, Li JS, et al. Cumulative radiation exposure and cancer risk estimation in children with heart disease. Circulation 2014;130(2):161-7.

[12] Harris RD, Marks WM. Compact ultrasound for improving maternal and perinatal Care in low-resource settings: review of the potential benefits, implementation challenges, and public health issues. J Ultrasound Med 2009;28(8):1067-76.

[13] Case RD. Haematoma block--a safe method of reducing Colles' fractures. Injury 1985;16(7):469-70.

[14] Carovac A, Smajlovic F, Junuzovic D. Application of ultrasound in medicine. Acta Inform Med 2011;19(3):168-71.

[15] Fricker R, Jupiter J, Kastelec $M$, et al. Nonoperative treatment - cast for extraarticular undisplaced fracture of the radius. 2021. Available from: https://surgeryreference.aofoundation.org/orthopedictrauma/adult-trauma/distal-forearm/extraarticularundisplaced-fracture-of-the-radius/nonoperativetreatment-cast

[16] Sabzghabaei A, Shojaee M, Dolatabadi AA, et al. Ultrasound-guided reduction of distal radius fractures. Emerg (Tehran) 2016;4(3):132-5.

[17] Marincek B, Dondelinger RF. Emergency radiology imaging and intervention. 2007th Edition. Springer 2006.

[18] Lalone EA, Grewal R, King GJW, et al. A structured review addressing the use of radiographic measures of alignment and the definition of acceptability in patients with distal radius fractures. Hand (N Y)2015;10(4):62138.

[19] Solgaard S. Angle of inclination of the articular surface of the distal radius. Radiologe 1984;24(7):346-8.

[20] Ang SH, Lee SW, Lam KY. Ultrasound-guided reduction of distal radius fractures. Am J Emerg Med 2010;28(9):1002-8.

[21] Kodama N, Takemura $\mathrm{Y}$, Ueba $\mathrm{H}$, et al. Ultrasoundassisted closed reduction of distal radius fractures. J Hand Surg Am 2014;39(7):1287-94.

[22] Weinberg ER, Tunik MG, Tsung JW. Accuracy of clinicianperformed point-of-care ultrasound for the diagnosis of fractures in children and young adults. Injury 2010;41(8):862-8.

[23] Hauger 0, Bonnefoy O, Moinard M, et al. Occult fractures of the waist of the scaphoid: early diagnosis by highspatial-resolution sonography. AJR Am J Roentgenol 2002;178(5):1239-45.

[24] Heiner JD, Proffitt AM, McArthur TJ. The ability of emergency nurses to detect simulated long bone fractures with portable ultrasound. Int Emerg Nurs 2011;19(3):120-4.

[25] Jankharia GR. Commentary-radiology in India: the next decade. Indian J Radiol Imaging 2008;18(3):189-91.

[26] Mahajan A, Samuel S, Saran AK, et al. Occupational radiation exposure from $\mathrm{C}$ arm fluoroscopy during common orthopaedic surgical procedures and its prevention. J Clin Diagn Res 2015;9(3):RC01-4.

[27] Abu-Zidan FM, Hefny AF, Corr P. Clinical ultrasound physics. J Emerg Trauma Shock 2011;4(4):501-3. 